\title{
Ethanol Decreases the Expression of Pituitary Adenylate Cyclase Activating Polypeptide in Rat Testes
}

\author{
Phil-Ok $\mathrm{KOH}^{1) *}$, Chung-Kil $\mathrm{WON}^{1)}$ and Jae-Hyeon $\mathrm{CHO}^{1)}$ \\ ${ }^{1)}$ Department of Anatomy, College of Veterinary Medicine, Institute of Agriculture and Life Sciences, Gyeongsang National University, \\ 900 Gajwa-dong, Jinju 660-701, South Korea
}

(Received 22 August 2005/Accepted 24 January 2006)

ABSTRACT. The present study was designed to evaluate the effect of ethanol on pituitary adenylate cyclase activating polypeptide (PACAP) expression in adult rat testes. Ethanol ( $3 \mathrm{~g} / \mathrm{kg}$ i.p., $15 \% \mathrm{v} / \mathrm{v}$ in saline) was administrated to adult male rats for 10 days. Using northern blot analysis, we elucidated the decrease of PACAP mRNA in rat testes by ethanol administration. The level of PACAP mRNA was decreased by $46.5 \%$ in testes of the ethanol-treated animals, compared to that of saline-treated animals. In particular, ethanol exposure decreased the expression of PACAP mRNA and protein in developing germ cells, which are sperm cell progenitors. Thus, our findings suggest that the decrease of PACAP in developing germ cells by ethanol administration may contribute to the suppression of male reproductive activity.

KEY WORDS: ethanol, PACAP, testes.

J. Vet. Med. Sci. 68(6): 635-637, 2006

Ethanol is among the most widely abused drugs. It can suppress reproductive function and sexual behavior in laboratory animals and humans $[1,6]$. Also, chronic ethanol exposure for 30 days has been shown to cause testicular atrophy and accessory reproductive organ dysfunction in adult male rats [3]. Another study showed that ethanol exposure decreases male reproductive ability through the reduction of testosterone production and the suppression of spermatogenesis and steroidogenesis [13].

In testicular germ cells, pituitary adenylate cyclase activating polypeptide (PACAP) has been shown to stimulate cAMP production and to contribute to spermatogenesis [5, 9]. PACAP has considerable homology with secretin, glucagon, vasoactive intestinal peptide, and growth hormone releasing hormone $[10,11]$. PACAP has been found in regions of the central nervous tissues as well as peripheral tissues $[2,7]$. The highest concentration of PACAP is found in adult testes, and the amount of PACAP in two testes exceeds that of the whole brain [2]. In adult rat testis, PACAP was stage specifically expressed in seminiferous tubules and the highest amount of PACAP was detected in the developing germ cells at stage III-VII of the epithelial cycle $[5,8,9]$. These studies also demonstrated that PACAP is closely related to spermatogenesis. Thus, we propose that ethanol suppress male reproductive ability through the down-regulation of PACAP in rat testes. To date, however, the effect of ethanol on PACAP expression in rat testes has not been elucidated. Therefore, the present study was performed to provide this information.

Male Sprague-Dawley rats (220-250 g, 12 weeks age) were purchased from Samtako Co. (Animal Breeding Center, Korea) and were randomly divided into two groups,

\footnotetext{
* Correspondence to: Koh, P.O., Department of Anatomy, College of Veterinary Medicine, Gyeongsang National University, Jinju 660-701, South Korea.
}

saline-treated group and ethanol-treated group ( $n=10$ per group). Animals were maintained under controlled temperature $\left(25^{\circ} \mathrm{C}\right)$ and lighting (14/10 light/dark cycle) and all experiments were performed in accordance with the Principles of Laboratory Animal Care. Ethanol (3 g/kg, 15\% v/v in saline) was administrated daily (08:00-09:00 hr) intraperitoneally for 10 days, and the same volume of saline was administrated for the controls [6]. For northern blot analysis, rats ( $n=5$ per group) were decapitated and testes were removed quickly and frozen in liquid nitrogen. Total RNA $(30 \mu \mathrm{g})$ was denatured, electrophoresed in a $1.2 \%$ agarose denaturing gel, and transferred to nylon membranes (Nytran, pore size: $0.45 \mu \mathrm{m}$; Schleicher \& Schuell, Keene, NH, U.S.A.). The membrane was prehybridized with gentle shaking at $42^{\circ} \mathrm{C}$ for $2 \mathrm{hr}$ in a buffer containing $50 \%$ deionized formamide, $5 \times$ Denhardt's solution, $5 \times$ sodium chloride/sodium phosphate/EDTA buffer (SSPE), and 0.1\% SDS. The ${ }^{32} \mathrm{P}-\mathrm{UTP}$ labeled probe was added to the hybridization buffer and hybridized at $60^{\circ} \mathrm{C}$ for $24 \mathrm{hr}$. The membrane was washed and exposed with $\mathrm{X}$-ray films at $-70^{\circ} \mathrm{C}$ for 2 days. The intensity analysis was carried out using SigmaGel 1.0 (Jandel Scientific, San Rafael, CA, U.S.A.).

For in situ hybridization and immunohistochemical studies, animals ( $n=5$ per group) were anesthetized with pentobarbital (12 mg/100 g, i.p) and perfused through the left cardiac ventricle with $4 \%$ paraformaldehyde in $0.1 \mathrm{M}$ PBS. Testes were removed and sliced in $10 \mu \mathrm{m}$ thickness on cryomicrotome. Tissue sections were treated with Proteinase K and an acetylation solution. Subsequently, they were covered with prehybridization buffer containing 50\% formamide and incubated at $37^{\circ} \mathrm{C}$ for $1 \mathrm{hr}$. Hybridization with the ${ }^{35}$ S-labeled PACAP cRNA probe (rat PACAP ${ }^{971-1171}, 5 \times$ $10^{5} \mathrm{cpm} /$ slide) was performed at $60^{\circ} \mathrm{C}$ for $24 \mathrm{hr}$. Antisense and sense cRNA probes were prepared using in vitro transcription kit (Promega, Madison, WI. U.S.A.). Tissue slides were treated with RNase A $(20 \mu \mathrm{g} / \mathrm{m} l)$, washed, and dehy- 
drated in an ascending alcohol series. The slides were dipped into NTB2 emulsion (Eastman Kodak Co., Rochester, NY, U.S.A.), exposed at $4^{\circ} \mathrm{C}$ for 2 weeks, developed in Kodak D19 developer, and counterstained with hematoxylin. The slides were observed under a dark and a bright field microscope, and then photographed.

For the immunohistochemical study, sections were blocked with $1 \%$ normal goat serum in PBS for $1 \mathrm{hr}$ and then incubated with rabbit anti-PACAP 38 antiserum (1:100 in PBS, Peninsula Laboratories Inc., Belmont, NC, U.S.A.) at $4{ }^{\circ} \mathrm{C}$ for $18 \mathrm{hr}$ in a humidified chamber. As a negative control, normal goat serum was used instead of anti-PACAP 38 antiserum for antibody reaction. After washing with PBS, sections were incubated with biotin-conjugated goat anti-rabbit IgG (1:200 in PBS) for $1 \mathrm{hr}$, followed by avidinbiotin-peroxidase complex for $1 \mathrm{hr}$ from a Vector ABC Elite kit (Vector Laboratories Inc., Burlingame, CA, U.S.A.). Sections were washed with PBS, and incubated with diaminobenzidine tetrahydrochloride (DAB, Sigma chemical Co., St. Louis, MO, U.S.A.) solution with $0.03 \%$ hydrogen peroxidase for $3 \mathrm{~min}$. Slides were counterstained with hematoxylin and observed under microscope, and then photographed.

All data are expressed as mean \pm S.E.M. The results in each group were compared by one-way analysis of variance (ANOVA) followed by Student's $t$ test. The difference for comparison was considered significant at $P<0.05$.

Northern blot analysis showed that ethanol administration significantly decreased the level of PACAP mRNA in adult rat testes (Fig. 1). PACAP transcripts appeared to have a size of $1.2 \mathrm{~kb}$ in rat testes. Ethanol administration significantly reduced the level of PACAP by $46.5 \%$, compared with saline-treated group. The levels of PACAP mRNA were $3.61 \pm 0.31$ and $2.3 \pm 0.12$ in saline-treated and ethanol-treated animals, respectively.

In situ hybridization showed that PACAP mRNA was expressed at specific stages in seminiferous tubules. Positive cells of PACAP mRNA were observed in the developing germ cells at stages III-VII of the epithelial cycle. The strongest signals of PACAP mRNA were detected in spermatids at stage V to early stage VII of the cycle (Fig. 2A, B). Dark-field photomicrographs showed that PACAP mRNA was weakly expressed in ethanol-treated animals as compared to saline-treated animals (Fig. 2A, C). There was no detectable signal using sense probe as a negative control (Fig. 2E). Also, Fig. 3 shows that positive cells of the PACAP protein were strongly detected in spermatids near the lumen at stage V to early stage VII of the cycle (Fig. 3A, B). We observed that the PACAP immunoreactivity intensity appears only weakly in ethanol-treated animals as compared to that of saline-treated animals (Fig. 3C, D). No positive signals were detected in negative control (Fig. 3E).

Chronic ethanol exposure for 30 days has been shown to cause testicular atrophy and accessory reproductive organ dysfunction in adult male rats [3]. However, in this study, we did not demonstrate the significant change of testicular weight and the severe morphological defect in ethanol-

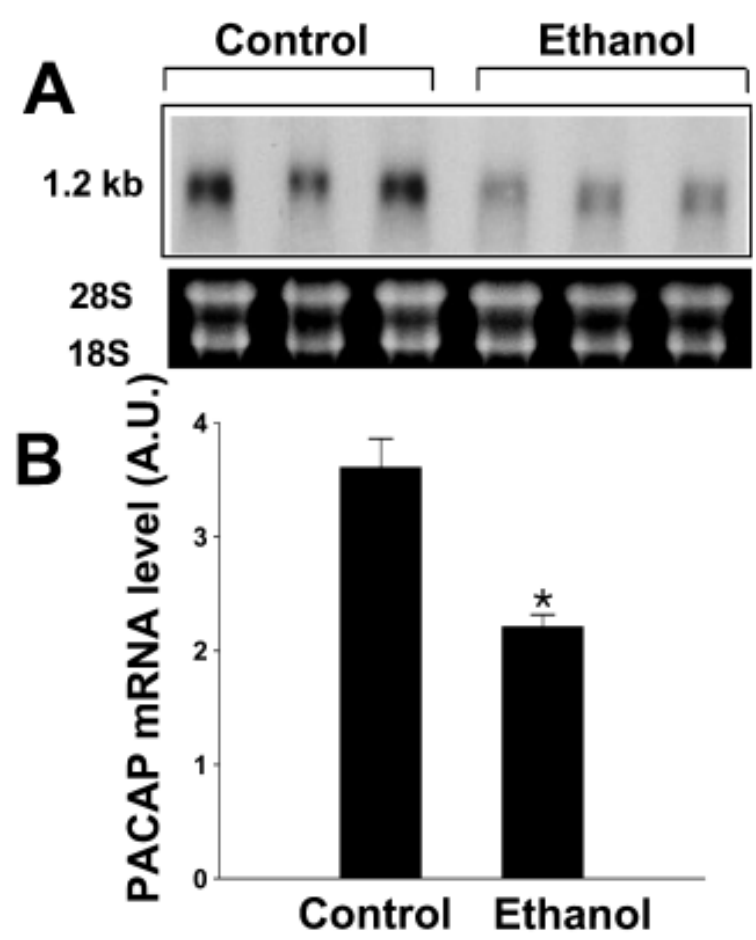

Fig. 1. Northern blot analysis of PACAP mRNA in the rat testis of saline- (Control) and ethanol-treated animals (Ethanol). A: Hybridization was performed with a ${ }^{32} \mathrm{P}$-labeled PACAP cRNA probe. The lower panel shows the $28 \mathrm{~S}$ and $18 \mathrm{~S}$ ribosomal RNA on an agarose gel stained with ethidium bromide. B: Densitometric analysis of PACAP mRNA levels is represented as an arbitrary unit (A.U.) that was normalized by $18 \mathrm{~S}$ RNA. Represented data: mean \pm S.E.M. $(n=5)$. $* P<0.05$ (vs. control).

treated rats. We consider that ethanol treatment for 10 days is insufficient for the testicular atrophy and the morphological defect. However, our previous study demonstrated that the degenerating germ cells increased in ethanol-treated animals, compared to that of saline-treated animals (unpublished data). Increased degenerating germ cells indicate the morphological defect including spermatogenesis impairment

It is widely accepted that PACAP stimulates cAMP production and contributes to spermatogenesis in testicular germ cells $[5,9]$. In this study, we elucidated that ethanol treatment markedly decreased the expression levels of PACAP mRNA and protein in developing germ cells of testes. PACAP mRNA and protein were expressed in the developing germ cells at stage III-VII of the epithelial cycle. The presence of PACAP in developing germ cells is in accord with previous studies $[5,9,14]$. Also, PACAP stimulates cell proliferation and survival and prevents cell death in various cells $[12,15]$. Moreover, previous study demonstrated that chronic alcohol abuse produces sexual dysfunction and impairs sperm production in both humans and animals [3]. This study demonstrated that ethanol exposure induced a decrease of PACAP expression in developing 

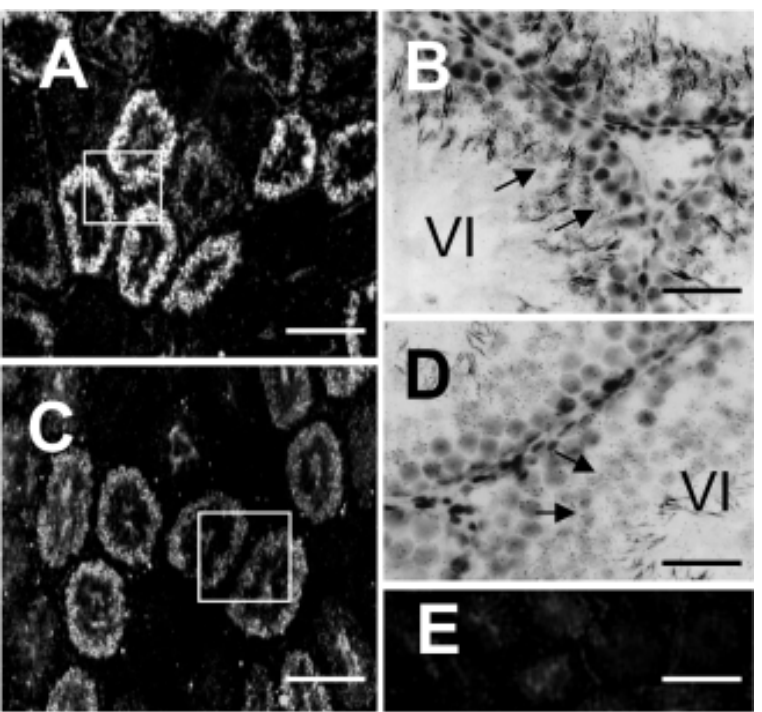

Fig. 2. Dark-field (A, C, and E) and bright-field (B and D) photomicrographs of PACAP mRNA in the rat testis of saline- (A and $\mathrm{B}$ ) and ethanol-treated animals (C and D) by in situ hybridization. Positive signals were observed in the seminiferous tubules. Intensive hybridization signals were observed in the round spermatids at the stages V-VII of the epithelial cycle. Bright-field photos indicate the square areas of darkfield. No positive signals were detected in negative control with a sense probe (E). Arrows indicate positive signals. Scale bars : A, C, and E, $100 \mu \mathrm{m}$; B and D, $25 \mu \mathrm{m}$.

germ cells of testes, which are sperm cell progenitors. Thus, our study suggests that decreased PACAP levels in rat testes as a result of ethanol exposure may be interfere with spermatogenesis.

Our data clearly show that ethanol administration decreased the levels of PACAP in adult rat testes. However, this study did not directly show how the decrease of PACAP expression contributes to the reduction of spermatogenesis. Nevertheless, previous studies provide strong supporting evidence that PACAP mediates spermatogenesis [5, 9]. Therefore, we suggest that the decrease of PACAP in developing germ cells by ethanol administration may be associated with the suppression of male reproductive activity.

ACKNOWLEDGMENT. This research was partly supported by fund from the Korea Science and Engineering Foundation (KOSEF R04-2003-000-10062-0).

\section{REFERENCES}

1. Abel, E. L. 1980. Drug Alcohol Depend. 5: 321-332.

2. Arimura, A., Somogyvari-Vigh, A., Miyata, A., Mizuno, K., Coy, D. H. and Kitada, C. 1991. Endocrinology 129: 27872789.

3. El-Sokkary, G. H. 2001. Neuro. Endocrinol. Lett. 22: 93-99.

4. Fadem, B. H. 1993. Alcohol Clin. Exp. Res. 17: 870-876.

5. Hannibal, J. and Fahrenkrug, J. 1995. Regul. Pept. 55: 111-

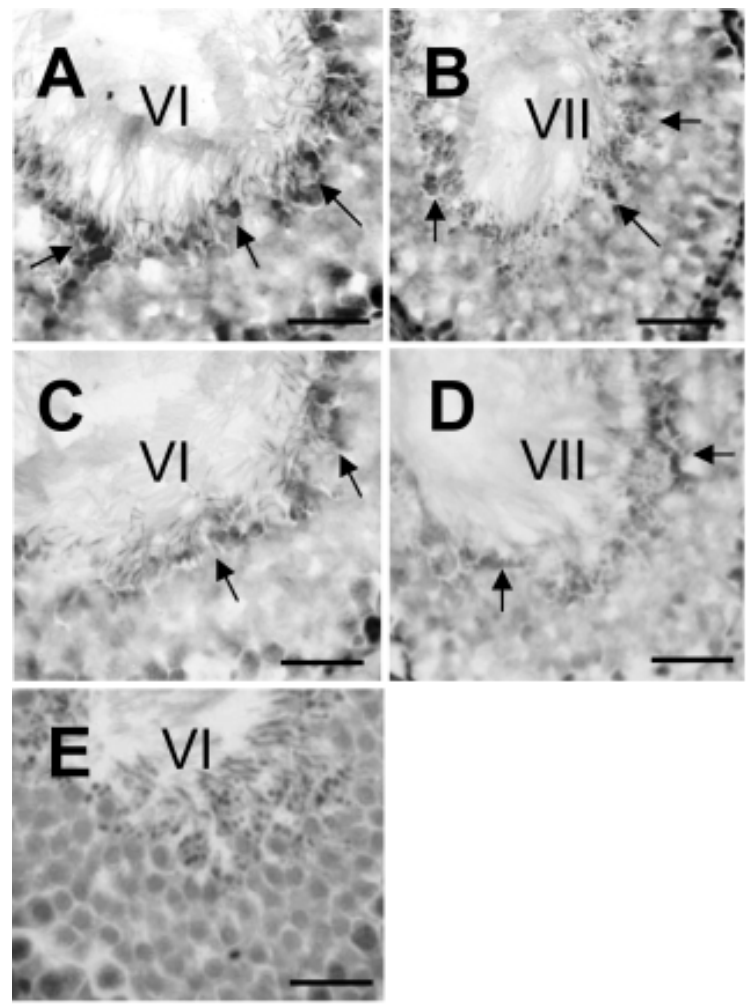

Fig. 3. Expression of PACAP protein in the rat testis of saline$(\mathrm{A}, \mathrm{B}$, and $\mathrm{E})$ and ethanol-treated animals $(\mathrm{C}$ and $\mathrm{D})$ by immunohistochemistry. Positive cells were observed in the round spermatids at the stage V-VII of the cycle. No positive cells were detected in a negative control (E). Arrows indicate positive signals. Scale bars : $25 \mu \mathrm{m}$.

115.

6. Kim, J. H., Kim, H. J., Noh, H. S., Roh, G. S., Kang, S. S., Cho, G. J., Park, S. K., Lee B. J. and Choi, W. S. 2003. Brain Res. 989: 91-98.

7. Koh, P. O., Kwak, S. D., Kang, S. S., Cho, G. J., Chun, S. Y., Kwon, H. B. and Choi, W. S. 2000. Mol. Reprod. Dev. 55: 379-386.

8. Koh, P. O., Noh, H. S., Kim, Y. S., Cheon, E. W., Kim, H. J., Kang, S. S., Cho, G. J. and Choi, W. S. 2003. Mol. Cells 15: 271-276.

9. Kononen, J., Paavola, M., Penttila, T. L., Parvinen, M. and Pelto Huikko, M. 1994. Endocrinology 135: 2291-2294.

10. Miyata, A., Arimura, A., Dahl, R. R., Minamino, N., Uehara, A., Jiang, L., Culler, M. D. and Coy, D. H. 1989. Biochem. Biophys. Res. Commun. 614: 567-574.

11. Miyata, A., Jiang, L., Dahl, R. R., Kitada, C., Kubo, K., Fujino, M., Minamino, N. and Arimura, A. 1990. Biochem. Biophys. Res. Commun. 170: 643-648.

12. Pesce, M., Canipari, R., Ferri, G. L., Siracusa, G. and De Felici, M. 1996. Development 122: 215-221.

13. Salonen, I. and Huhtaniemi, I. 1990. Biol. Reprod. 42: 55-62.

14. Shioda, S., Legradi, G., Leung, W. C., Nakajo, S., Nakaya, K. and Arimura, A. 1994. Endocrinology 135: 818-825.

15. Shivers, B. D., Gorcs, T. J., Gottschall, P. E. and Arimura, A. 1991. Endocrinology 128: 3055-3065. 